\title{
Multistakeholder Initiatives in Global Production Networks Naturalizing Specific Understandings of Sustainability Through the Better Cotton Initiative
}

\author{
Riisgaard, Lone; Lund-Thomsen, Peter; Coe, Neil M.
}

Document Version

Accepted author manuscript

Published in:

Global Networks

DOI:

10.1111/glob.12251

Publication date:

2020

License

Unspecified

Citation for published version (APA):

Riisgaard, L., Lund-Thomsen, P., \& Coe, N. M. (2020). Multistakeholder Initiatives in Global Production Networks: Naturalizing Specific Understandings of Sustainability Through the Better Cotton Initiative. Global Networks, 20(2), 211-236. https://doi.org/10.1111/glob.12251

Link to publication in CBS Research Portal

\section{General rights}

Copyright and moral rights for the publications made accessible in the public portal are retained by the authors and/or other copyright owners and it is a condition of accessing publications that users recognise and abide by the legal requirements associated with these rights.

Take down policy

If you believe that this document breaches copyright please contact us (research.lib@cbs.dk) providing details, and we will remove access to the work immediately and investigate your claim. 


\section{Multistakeholder Initiatives in Global Production Networks: Naturalizing Specific Understandings of Sustainability Through the Better Cotton Initiative} Lone Riisgaard, Peter Lund-Thomsen, and Neil M. Coe

Journal article (Accepted manuscript*)

\section{Please cite this article as:}

Riisgaard, L., Lund-Thomsen, P., \& Coe, N. M. (20२0). Multistakeholder Initiatives in Global Production Networks: Naturalizing Specific Understandings of Sustainability Through the Better Cotton Initiative. Global Networks, 2a2), 211-236. https://doi.org/10.1111/glob.12251

This is the peer reviewed version of the article, which has been published in final form at DOI: https://doi.org/10.1111/glob.12251

This article may be used for non-commercial purposes in accordance with Wiley Terms and Conditions for Self-Archiving

* This version of the article has been accepted for publication and undergone full peer review but has not been through the copyediting, typesetting, pagination and proofreading process, which may lead to differences between this version and the publisher's final version AKA Version of Record. 


\title{
Multistakeholder Initiatives in Global Production Networks: Naturalizing specific understandings of sustainability through the Better Cotton Initiative
}

\begin{abstract}
In recent years various academics, consultants, companies and NGOs have advocated a move towards more cooperative approaches to private sustainability standards in order to address the widely identified shortcomings of the compliance paradigm. But is it possible to address these limitations by moving towards stakeholder inclusion and capacity building while at the same time catering to the demands of lead firms supplying the mainstream market? This article analyses how the Better Cotton Initiative (BCI) seeks to do just that, in the process identifying three key tensions and competing policy concerns that standard-setters have had to grapple with: stakeholder inclusion vs. process-control/efficiency; (b) stringency of the standard vs. scale of production; and (c) capacity building vs. auditing. Combining theoretical considerations about governance in Global Production Networks (GPNs) with a convention theory perspective, we explore these inherent tensions and show that due to pre-existing power relations in the cotton GPN, it is hard to develop more cooperative approaches as market and industrial values tend to win out despite efforts to follow current best practice on sustainability standard-setting.
\end{abstract}

Keywords: cotton, multistakeholder initiatives, global production networks, standards, convention theory, governance 


\section{Introduction}

Over the past two decades, multistakeholder initiatives (MSIs) have been created in response to growing criticism of the environmental and social impacts of various globally organized industries and a perceived government failure to address these concerns, particularly in developing country sourcing contexts (Locke, 2013; Auld et al. 2015). MSIs are often transnational in nature, and involve actors such as NGOs, businesses, business associations, UN agencies and labour organisations (Bernstein and Cashore, 2007).

The role of MSIs in governing sustainability concerns varies from guidelines and reporting initiatives (e.g. the UN Global Compact or the Global Reporting Initiative) to initiatives which set and verify or certify compliance with sustainability standards (such as the Forest Stewardship Council and the Roundtable on Sustainable Palm Oil) (Gilbert et al. 2011; Rasche, 2012). The institutional features of MSIs usually include an executive board, an assembly or council representing different stakeholder interests, a technical advisory committee and an executive director with a secretariat to handle the daily operations (Ponte, 2013; Fransen, 2011).

The rise in MSIs also reflect calls by various academics, consultants, corporations and NGOs for more cooperative types of sustainability initiatives that incorporate civic expectations about participation and equality (Lund-Thomsen and Lindgreen, 2014). MSIs have been promoted as a potential answer to some of the now widely identified shortcomings of the hitherto dominant compliance paradigm, including the high cost for suppliers of implementing standards, the limited impact of auditing, the lack of capacity building of local suppliers and their workforce, as well as the weak inclusion of workers and smallholders (Locke, 2013; Raynolds 2018). Thus, what is currently considered best practice in sustainability standard making has been converging around ideals of cooperation, inclusion and transparency (most notably institutionalized by the coalition of standard organizations, the ISEAL Alliance - see Cheyns and Riisgaard 2014). 
At the same time, the last decade has seen a substantial change in how businesses engage with sustainability governance. Lead firms are embracing sustainability on an unprecedented scale to protect and enhance brand value in the face of NGO and media criticism and to optimize control over their supply chain by focusing on issues of quality, productivity, traceability and security of supply (Ponte 2019, Levy et al. 2016, Dauvergene and Lister 2013, Humes 2011). While on the one hand, this offers unprecedented opportunities for ratcheting-up sustainable production, on the other hand, an emerging literature warns us that in the process lead firms increase their power in GPNs and shift the purpose and goal of sustainability away from more radical environmental and social goals (like addressing unfairness in global trade) towards the need to create business value (Ponte 2019, Levy et al. 2016, Dauvergene and Lister 2013, Humes 2011).

In this article we investigate how the large scale business adoption of sustainability plays out in the global cotton industry, particularly in the context of the Better Cotton Initiative, a scheme that has not yet received much attention in the literature on sustainability governance (see Sneyd, 2014 for an exception). Large scale business adoption of sustainability, however, does not occur in a vacuum but rather builds on earlier experiences with sustainability initiatives in a context of increasing pressure to conform to best practice demands about cooperation, inclusion and transparency. As such, is it possible to address the limitations of the criticized compliance approach by moving towards cooperative methods while at the same time catering to the needs of lead businesses supplying the mainstream market?

This article contributes to the MSI in global production networks (GPNs) literature by analysing how the Better Cotton Initiative (BCI) seeks to do just that. We conceptualise the tensions and trade-offs that standard-setters have had to grapple with when seeking to move towards more cooperative approaches in a context of large scale business adoption. In short, this article makes 
four distinct contributions to the literature on MSIs in GPNs. First, in empirical terms, this is the first academic work analyzing the BCI standard formulation process which took place from 2003 to 2009. Second, in theoretical terms, the article identifies three institutional trade-offs - (a) stakeholder inclusion vs. process-control/efficiency; (b) stringency of the standard vs. scale of production; and (c) capacity building vs. auditing - that are likely to be present in standard systems that aim at mainstreaming large-scale, industry-wide transformation towards more sustainable forms of commodity production. Third, combining theoretical considerations about governance in GPNs with a convention theory perspective, we detail these trade-offs as tensions between different underlying values and thus different expectations about sustainability. The settlements reached between diverging values normalize new modes of GPN governance and will thus influence not only who is to be included or excluded in the sustainability strand of the GPN, but also how they are included and hence the distribution of benefits and costs of GPN participation. Fourth, we hypothesize that the identified dilemmas and resulting settlements create particular opportunities but also limitations in relation to what standard implementers can ultimately achieve on the ground in their interaction with standard beneficiaries (in this case, small scale cotton farmers and on-farm workers). In sum, this paper yield important insights into why it is inherently difficult for MSIs such as the BCI - which aims to make 30 percent of world cotton production more sustainable by 2020 - to deliver the expected results despite their efforts to follow current best practice in sustainability standard-setting.

The remainder of the paper is organized as follows. In Section 2, we present a brief overview of the global cotton industry and the role of the BCI within it. Section 3 outlines our methodology, while Section 4 develops a Convention Theory influenced GPN perspective on MSIs, detailing how standard makers have to negotiate and navigate three sets of inherent tensions in pursuing cooperative approaches to sustainability standard-making. In Section 5, we deploy this framing to 
analyze the evolution of the BCI standard-setting process while in Section 6 we conclude and reflect on the wider implications of our findings.

\section{The global cotton industry and the Better Cotton Initiative}

Cotton production provides livelihoods for about 250 million people worldwide and the majority is grown by smallholders on plots of mostly 1-2 hectares (Better Cotton Initiative 2015). The major producers of cotton are China, India, the United States, Pakistan, Brazil, Uzbekistan and Australia (see Figure 1), while the largest importers of cotton encompass China, Turkey, Bangladesh, Vietnam and Indonesia (USDA, 2016).

\section{< Insert Figure 1 here >}

The cotton GPN is highly complex, involving many players and several stages of production including ginning, spinning, dyeing and weaving. Once the fabric has been made, it is then cut and sewn into various types of garments. The cotton GPN is often highly opaque with buyers and sellers at different tiers of the network being unaware of the origin of the cotton and where it is ultimately consumed (Alexander, 2016). ${ }^{1}$ While Figure 2 offers a stylized overview of the cotton GPN, in reality cotton traverses a much more complex network; a gin, for example, receives cotton from multiple growers while spinners use a mixture of cotton that ranges in origin and quality to produce yarn.

\section{< Insert Figure 2 here >}

When trying to distill the constituent organizational structures and power relations, the production network for cotton can also be conceptualized as cotton trading (the segment from farmer to spinner) embedded within the broader apparel/textile production network (Quark, 2011; Talbot, 2009). The apparel GPN is often given as a key example of a buyer-driven GPN wherein 
large retailers and branded merchandisers play a powerful role - generally characterised as that of the "lead firm" - in the governance of global production and distribution. Although these buyers typically own few production facilities, if any, the volume of their purchasing and associated market power provides them with a high degree of influence over suppliers to specify how, when, where, and by whom the goods they sell are produced. However, when looking at the actual cotton provision and trade, other actors - in particular traders - take prominence. Indeed Gibbon (2001) has called the raw material segment "trader driven". The lead firms in this segment are transnational merchants who link cotton-producing countries with cotton-consuming countries. There are thousands of local and regional merchants while only a small number of merchants conduct the transnational trade (by the early 2000s, about ten companies handled more than twothirds of the transnational trade in cotton) (Quark, 2011). However one depicts the cotton GPN, the role of small scale cotton producers is a subordinate one and, in a developing country context, small farmers face numerous challenges such as price fluctuations, indebtedness and crop failure without access to insurance or other economic protections or social safety nets.

Addressing the sustainability-related impacts of production in this nontransparent and complex production network is a challenging endeavor. Nevertheless, over the last three decades, different sustainability standard systems have been formed with precisely this aim (Ferrigno, 2016). Sustainability in cotton started with Organic cotton in the late 1980s and Fairtrade in 2004. Both of these initiatives aim at changing the negative impacts of production (and improving the livelihoods of small producers) via a consumer-paid premium on certified produce. In 2005, Cotton made in Africa (CMIA) entered the market, followed by Better Cotton (BCI) in 2009 (PAN UK et al. 2017). With the entrance of the latter standard aimed explicitly at the mainstream market, volumes of cotton grown as sustainable have increased dramatically. Accounting for less than 1 percent of global cultivation in 2008/9, by 2015/16 it had reached 13 percent (although only an estimated fifth of the 13 percent is actually being bought as more sustainable). Of the 
$2,635,000 \mathrm{MT}$ of cotton grown as sustainable in 2015/16, the overwhelming proportion was BCI (with 2,500,000 MT including CMIA which is recognized as equivalent to the BCI) (Ferrigno 2016, PAN UK et al. 2017). By the end of the 2016/17 growing season, the BCI had licensed approximately 1.3 million farmers that produced more than 3,262,000 MT of Better Cotton lint in 21 countries, accounting for 14 percent of the global cotton supply (BCI 2018).

After a six-year standard-making process, the BCI was officially launched in 2009-10 as an independent organization along with the first Better Cotton Global Standard. The BCI was formed with the aim of developing its cotton as a sustainable mainstream commodity. The BCI is headquartered in Switzerland and has regional offices in various parts of the world. In charge of the BCI's everyday operations, its Secretariat is headed by a CEO and a support team. In terms of its current governance structure, the BCI Council is an elected board which represents different member interests that have equal representation on the board (three seats each) including civil society representatives, retailer/brands, farmer producer associations, textile and garment suppliers and manufacturers in addition to two independent representatives. ${ }^{2}$ The Better Cotton Standard System is furthermore made up of six different elements: the BCI production principles and criteria, its capacity building approach, its assurance program, its chain of custody approach, its claims framework, and its way of measuring 'results and impacts'. The BCI's main production principles are demonstrated in Figure 3.

\section{$<$ Insert Figure 3 here >}

The BCI standard-setting process was launched at the initiative of the World Wide Fund for Nature (WWF) in 2003-2004. The WWF had undertaken a joint research project with the International Finance Corporation (IFC) in 2000-2002 which sought to identify the environmental impacts of ten agricultural commodities. Subsequently, the WWF selected palm oil, soy, sugar 
cane and cotton as the commodities around which the organization wanted to develop MSIs due to the sustainability impact, financial sector traction, and added value that IFC/WWF sector-wide initiatives could provide for each commodity (IIED/Proforest, 2004). The BCI standard-setting process was launched as part of this process.

\section{Methodological Considerations}

This article studies the formulation of the Better Cotton Initiative which took place between 2003 and 2009. As such it does not address later revisions of the BCI standard or the BCI initiative. In the process of tracing the central persons that had been involved in the negotiation of the standard system between 2003 and 2009, we were helped by the former head of the BCI who introduced our research team to the relevant brand, NGO, government and other stakeholders. As our study had a main focus on how the BCI has been formulated, implemented and monitored as a standard system in Pakistan and India, we also reached out to national-level stakeholders in both countries who had been involved in regional working groups in 2006-2008, wherein the BCI secretariat had discussed the draft BCI production principles and criteria with a variety of intergovernmental, governmental, private sector, NGO, trade union, farmer organization and other stakeholders from the countries in question. We sought information from interviewees about: (i) their role in the standard formulation process and possible subsequent involvement in the BCI; (ii) the key meetings in the standard-setting process; (iii) the main priorities of the various stakeholders and their evolution over time; (iv) the major topics of discussion and contention and (v) the timing and ways in which key decisions were reached.

Interviews were undertaken in person or via Skype/phone and either they were tape recorded or detailed interview notes were taken and sent back to interviewees for feedback. We triangulated the information obtained through interviews with a complete file of background materials and notes from all the meetings that took place in the BCI steering committee and regional working 
groups between 2003 and 2009. We also reviewed the websites of the BCI and its brand, NGO and other members for information about their involvement in the BCI from 2003 onwards. We obtained feedback from the BCI secretariat, a key brand and a key NGO member of the BCI on earlier versions of this article which were used to ensure data accuracy and cross-check our interpretations of the BCI standard formulation process.

\section{A convention theory influenced GPN perspective on MSIs}

The compliance based paradigm ${ }^{3}$ - which can be characterized as an approach strictly controlled by lead firms who define and govern sustainability at a distance while pushing the cost of compliance towards suppliers - has been widely criticized. To address this, various academics, consultants, retailers and NGOs are increasingly advocating a turn towards a cooperation-based approach to working with sustainability standards in GPNs. This ideally is thought to involve: (a) the need to review the purchasing practices of international buyers so that these do not adversely affect the ability of their suppliers to comply with sustainability standards; (b) the encouragement of buyers to invest in capacity building for both local producers and their workforces; (c) that auditing moves towards more participatory methods including cooperation with local actors such as NGOs or trade unions that could help lead firms improve conditions at the base of GPNs; and (d) engagement in multistakeholder initiatives to ensure the inclusion of all relevant stakeholders (Locke and Romis, 2007; Cheyns and Riisgaard, 2014; Ponte, 2013; Lund-Thomsen and Lindgreen, 2014). The degree to which these features have been adopted in practice is questionable (Lund-Thomsen \& Lindgreen, 2014), however the discourse of cooperation is widely applied and particularly the call for inclusion can be witnessed in the sharp rise of MSIs (Bartley, 2011).

In this article, we use GPN analysis as a framing device for understanding how MSIs are formulated. GPN analysis has been helpful in understanding broader processes of economic 
globalization, particularly the transnational organization of industries and the role that multinational corporations play in orchestrating these networks (Yeung and Coe, 2015). While a lot of focus has been on how multinational corporations design and govern supplier networks in developing countries (Humphrey and Schmitz, 2002; Gereffi et al. 2005), GPN analysis encompass the entire network of actors that tend to be involved in controlling interfirm transactions including states, NGOs, trade unions and international organizations (Lund-Thomsen and Coe, 2015). Moreover, GPN analysis has emphasized the evolutionary nature of these networks and the embeddedness of GPNs in the local institutional contexts where they touch down (Coe and Yeung, 2015).

In this article, we argue that MSIs play a key role in the governance of GPNs. In the GPN (and the related Global Value Chain) approach, governance has been characterized in at least three different ways, namely governance as (a) 'driving' ; (b) 'coordinating' ; and (c) 'normalizing' (Gibbon et al., 2008). The view of governance as driving can be understood as 'authority and power relationships that determine how financial, material, and human resources are allocated and flow within a chain' (Gereffi, 1994: 97). In this understanding of governance, the focus is on how lead firms drive the entire chain of actors. In the conception of governance as coordination, the analytical focus is narrowed down to a more specific interest in the links between lead firms and their first-tier suppliers (Gereffi et al. 2005). In relating GPN governance to MSIs in this article, we draw upon the third conception of governance that sees it as a form of 'normalizing'. However, we argue that this has to be seen in the context of GPN governance as 'driving'.

Our research showed that in the context of the cotton GPN, the ability of lead firms to exercise control over lower-level actors in the network is limited as the bottom tiers of the cotton GPN are often 'out of reach' for lead firms, or simply nontransparent, with lead firms not knowing the origin of the cotton used in their products nor being able to directly influence farmer practices. 
The recent embracing of sustainability by key players in the cotton industry needs to be seen in this context as buyers - through multistakeholder initiatives - seek to extend their power beyond first-tier suppliers to the very base of the GPN, i.e. the links between cotton farmers and ginning factories (Riisgaard et al. 2017; Lund-Thompsen et al, 2018).

Based on our research, we find that this need for extending GPN governance beyond lead firmfirst-tier supplier interactions in the cotton GPN arises from several interrelated factors. First, lead firms have been concerned about securing their source of primary commodity supply -i.e. cotton - at a time when production worldwide has been affected by issues such as climate change and water shortage (see also Makhdoom et al. 2011). Second, lead firms have also been unable to control the quality of the cotton produced with contamination of the cotton grade being a major concern in key production regions (see also FAO/ICAC 2015). Third, cotton production has been associated with highly unsustainable production practices such as very high levels of water usage and excessive use of pesticides which not only endanger farmer and worker health in local production regions but could also have negative effects on end consumers (for instance, resulting in skin irritation) and cause potential brand reputation risks (Lund-Thomsen et al. 2018). Fourth, many lead firms have little knowledge of where their cotton-based products originate from. As such, due to lack of transparency in the cotton GPN, lead firms have been keen on increasing the visibility in ways that would allow them to exercise control over local cotton production practices. These observations concur with emerging research from other GPNs (e.g. Ponte 2019, Levy et al 2016, Dauvergene and Lister 2013, Humes 2011) which argues that lead firms are now actively using sustainability in order to protect and enhance brand value and to optimize control over their supply chain by focusing on issues of quality, productivity, traceability and supply chain resilience. 
Given this context of buyer needs and interests with regards to driving the cotton GPN, we now turn to an understanding of GPN governance as 'normalizing'. This understanding contains important elements of self-regulation, emphasizing the role that ideas play in GPN governance (Levy, 2007; Dallas et al. 2017). Work in this area has zoomed in on how notions of quality (broadly understood) are interpreted and negotiated, and compromises reached about its meaning (Nadvi, 2008; Quark, 2011). Hence, the processes through which particular ideas about quality are shaped, given content, measured and operationalized are understood to be at the heart of how power relations are shaped and governance exercised within GPNs (Dallas et al. 2017; Ponte, forthcoming).

Extensive work in this area has demonstrated how GPN governance can be influenced by corporate social responsibility interventions (Lund-Thomsen and Lindgreen, 2014), MSIs (LundThomsen and Nadvi, 2010) and sustainability standards (Cheyns and Riisgaard, 2014; Ponte, forthcoming). Key to understanding GPN governance as 'normalizing' is thus not only the role of lead firms in qualifying particular understandings which influence conditions of production and exchange. It is equally important to analyze the counter-actions of other GPN network actors such as states, NGOs, trade unions, and communities that challenge and sometimes alter the status quo. In fact, we concur with Dallas et al. (2017: 7) who state that GPN governance as normalizing "has also broadened the possible set of governing actors beyond lead firms and suppliers, and how they exercise power in GVCs. The result is a more nuanced view of how buyer power is wielded, including instances where its expression can be disguised".

In this article, we argue that MSIs can also be perceived as sites where wider sets of stakeholders seek to contest buyer power. Hence, sustainability standard formulation processes in MSIs are not only circumscribed by the economic interests of lead firms (GPN governance as 'driving'), but 
also involve negotiation over particular conventions that ought to guide export-oriented production in developing countries (GPN governance as 'normalizing').

To help us unpack these underlying normative ideals we adopt a convention theory perspective. According to Boltanski and Thévenot (2006), specific expectations about economic coordination are normalized and institutionalized through systems of qualification (also called conventions). These conventions provide systems of justification within which particular forms of economic action are attributed value. Four conventions are commonly identified, namely 'domestic', 'industrial', 'market' and 'civic'. ${ }^{4}$ The fundamental principles of these conventions are 'tradition', 'efficiency', 'cost' and 'collective welfare', respectively. The four conventions correspond to different ways of characterizing the common good based on: 'market' competition focusing on price; 'industrial' efficiency based on scientific methods and standardization; 'domestic' trust based on personal relations; and 'civic' solidarity based on social and ecological welfare commitments and aiming at greater equality (Boltanski and Thévenot, 2006; Raynolds, 2017; Gibbon and Riisgaard, 2014).

On the one hand, convention theory enables us to analyze inherent tensions in MSIs between diverging conceptualizations related e.g. to inclusion and cooperation versus control and efficiency (GPN governance as 'normalizing') and, on the other hand, how vested interests linked to actor positions in the wider GPN affect the compromises that are forged (GPN governance as 'driving'). As argued by Raynolds (2017), convention theory potentially offers a deeper analysis of competing logics in MSIs by focusing greater attention on the normative foundations of economic activity in GPNs.

Conventions are usually found not in ideal but rather partly institutionalized and hybrid forms. While the dominant form of contemporary global economic organization is a combination of 
market and industrial conventions other compromises can also be found. Analyzing Fairtrade certification, for instance, Raynolds (2017) shows the inherent compromises between market and industrial conventions with domestic and civic expectations. More generally, one can argue that sustainability standards will to a degree draw on civic expectations as the standards aim in some form or other to advance social and ecological welfare. However, as sustainability standards also operate in the contemporary global economy, compromises between industrial, market and civic norms are to be expected. The precise form of the settlements reached, however, can take many different forms and are likely to be only momentary as contestations over the meaning and practice of sustainability are ongoing (Raynolds 2017; Levy et al. 2016).

From a convention theory perspective, MSIs reflect settlements between normative orders as quality (here in the sense of the conditions of cotton production) is evaluated in different ways depending on which convention is used to justify it (Ponte and Gibbon 2005). At the same time, the settlements reached will influence not only who is to be included or excluded in the GPN, but also the distribution of benefits and costs of GPN participation. High stakes and competing rationales are therefore involved when MSI systems are formulated. The diverging conceptualizations are illustrated in what we describe - based on the interrelated continuums shown in Figure 4 - as competing policy rationales that MSIs need to navigate between in the process of contested GPN governance.

\section{< Insert Figure 4 here >}

The first continuum relates to the basic question of who should be included/excluded from the process of 'normalizing' GPN governance. We describe this first continuum as running between civic expectations about 'stakeholder inclusion' and industrial rationales concerning 'process efficiency and control'. The rapid proliferation of MSIs can be seen as a response to growing 
criticism of the non-inclusive nature of most previous private standards (e.g. Gibbon and Lazaro, 2010; Nelson and Tallontire, 2014). This criticism was particularly strong when directed at the exclusionary effects of agricultural sustainability standards on producers in the South and on marginalized actors, especially smallholders. As a result, many standards initiatives have begun to recognize exclusion as a problem and sought to make their standards more inclusive, particularly at the levels of standard-setting and governance.

A defining feature of MSIs and thus also of the BCI is therefore the multistakeholder nature of the standard-setting process. MSIs generally claim to be inclusive of all relevant stakeholder categories, to be fully transparent and to make decisions based on consensus (Loconto and Fouilleux, 2013; Ponte, 2013; Cheyns and Riisgaard, 2014). However, involving multiple stakeholders in standard-setting processes can also be highly time-consuming and conflictual. Furthermore, the ability of standard makers to guide the standard-setting process (and thus the end result) in particular directions becomes more challenging with higher levels of stakeholder participation, especially in decision-making procedures. Hence, an important competing concern is maintaining process efficiency and regulatory control in the multistakeholder standard-setting process, i.e. ensuring that the negotiation process amongst the involved parties actually moves forward, and that a standard system is eventually formulated (while kept in line with certain key priorities).

The commitment to multistakeholding relates to the narrative that standards reached via multistakeholding are "better" and more legitimate because they take into consideration the interests of diverse actors in GPN governance. This narrative assumes that it is possible to achieve a high degree of coincidence between the interest of both society and business - and between diverse actors in the GPN. Critics have, however, highlighted how exclusion of marginalized actors and ideas works in subtle ways through MSIs accepting specific forms of 
engagement, knowledge and debate practices, often drawing on industrial rationales about expediency and decision-making efficiency (e.g. Cheyns and Riisgaard, 2014). Thus, in addition to civic expectations, the stakeholder inclusion paradigm also rests on a 'liberal grammar' of stakeholders negotiating for their specific interests (e.g. Cheyns, 2014). ${ }^{5}$

The process of stakeholders negotiating aspects of GPN governance in MSIs is also related to a second continuum. Here MSIs navigate between industrial concerns with 'scale of production' and civic concerns about 'stringency of the standard'. Several studies have pointed to an inherent trade-off between the stringency of the principles of sustainable production and the size of the standard program (e.g. Ingenbleek and Meulenberg, 2006; Macdonald, 2007), with the key argument being that the more stringent the standard (in terms of both the range and depth of sustainability issues covered), the more difficult and costly it is for farmers to convert to and comply with. This tends to result in a smaller number of participant farmers. At the same time, large buyers tend to be concerned with industrial conventions about stability and volume as well as market concerns of unit costs, meaning they often require a certain scalability (Riisgaard, 2011).

However, in addition to large buyers, governmental donor agencies, NGOs and private charities may also push for scale. This is because scalability relates to an industrial narrative of what constitutes significant change. The narrative thus posits that change is only significant if it is scalable. However, the scalability rationale is also closely related to market concerns about costs and prices. In more niche standards, such as Fairtrade and organic, there is often a civic expectation about providing local producers with an above market rate price. Here, the expectation is that this will help local producers to obtain a somewhat larger share of the total value of a commodity produced in a given GPN and that sustainability releases a quality premium that consumers are willing to pay for. 
In more mainstream standards (such as the $\mathrm{BCI}$ ), the focus will be on ensuring that sustainable commodity production is done without providing the intended beneficiaries - i.e. local producers - an above market rate price for their products. Industrial arguments about efficiency and quality gains posit that it will be possible to produce such products without any price increase. However, the commitments of mainstream MSIs to sell sustainable products without any price increase are in themselves a reflection of structural power dynamics in GPNs. On the one hand, international retailers and supermarkets may find that the majority of their customers are often unwilling to pay extra for sustainably produced commodities. Hence, in order to increase the sales of more sustainable products, it is vitally important from their point of view that the price does not increase. At the same time, a civic argument about redistribution within the GPN is most often not on the agenda of international retailers and brands (at least not redistribution towards producers). This means that local producers are asked to produce more sustainably, but this has to be done without providing them any higher prices for the extra effort in terms of time, energy, and finance that they invest in complying with a sustainability standard. In other words, this continuum concerns key GPN governance questions about what is to be produced in what quantity at which costs and under which sustainability conditions.

In terms of the processes through which GPN governance is normalized as part of MSI negotiations, we identify a third continuum between two aspects of MSI operations: 'capacity building' and 'auditing'. MSIs will often need to offer their intended beneficiaries such as farmers and/or workers capacity building in the MSI standard that they are supposed to be implementing. From this point of view, the focus is partly on helping poor farmers and workers to become capable of complying with a given standard, often using participatory approaches such as peer learning and involving the end beneficiaries in awareness-raising exercises about the social and environmental welfare ideas underlying a given standard system. This is clearly part of the 
cooperation paradigm to sustainability in GPNs involving civic expectations about rights, participation, responsibility and motivation. In addition, however, capacity building is oriented toward acquiring distinct industrial skills such as the capacity to measure, keep field books and make calculations.

At the same time, there is a concern that MSIs need to be able to prove that farmers actually comply with the standard, carry out the reported activities, and obtain the intended results. This involves industrial values of increased oversight and control which in a sense involves a "disempowering" of the intended beneficiaries. Under conditions of rapid upscaling, it may not be logistically feasible for MSIs to ensure sufficient quality (however defined) in capacity building of end beneficiaries and auditing of on-farm activities, particularly since scale is accompanied with market expectations about falling unit costs (in this case the cost of having a unit of cotton become more sustainable). This means that there is a direct trade-off between upwards accountability (towards MSI funders) and downwards accountability towards the intended beneficiaries of MSIs (local producers and workers). In other words, this continuum concerns traditional GPN governance questions related to unit costs, and to which methods should be applied to ensure sustainable production methods (i.e. capacity building and/or auditing).

In sum, individual standard initiatives will place themselves differently along these continuums. Drawing upon convention theory, we can analyze how the negotiations around standard setting more broadly, and the described dilemmas in particular, are not only circumscribed by the market power and economic interests of global brands and buyers, but also by the particular approaches to social and environmental sustainability which are seen as legitimate by different GPN actors that are members of MSIs. An analysis of how the dilemmas are navigated can offer important insights into how aspects of GPN governance are normalized in the formulation of MSI standards 
through processes of discussion and negotiation. In the following section we analyze how tensions related to these three continuums played out in the BCI standard-setting processes between 2003 and 2009.

\section{Competing Policy Imperatives in the Better Cotton Initiative Balancing Stakeholder Inclusion with Efficiency in Standard-Setting}

A key concern in the process of formulating the BCI standard was who should be included/excluded. In the initial stages of the BCI standard-setting process, civic expectations about securing inclusive, transparent and democratic forms of decision-making were invoked. However, in the words of a brand representative who took part in these early meetings:

“...it started off immediately by getting a wide spread of organizations to be represented but it was of course, Western organizations - European and American."

In this way, the BCI standard-setting process did not initially appear to differ from other MSIs that have been criticized for excluding the voices of Southern producers and workers in the process of normalizing GPN governance. Although Southern voices were thought to be represented via the participation of global NGOs, the voice of labour was not well-represented in the standard process either as the NGOs concerned with labour issues did not stay involved. This point was explained by a NGO representative:

"The least represented was on the social side. We had hoped that it would be because XX [a British development organization] had made a big campaign around cotton, subsidies and trade barriers at the Cancun meeting of the WTO that they would engage around this. But they had no interest in the long-term process of developing standards. So they did not continue to engage. YY [a Dutch development NGO] also had cutbacks in their social spending and their person was no longer involved so they did not stay engaged that long either. " 6 
At the second official meeting of the BCI in Utrecht, Netherlands in 2005, it was decided to structure the standard-setting process in a way that would seek to balance the need for efficiency in decision-making processes against the broader objective of ensuring the widest possible participation of stakeholders. It was discussed whether the Steering Committee that was to lead the standard-setting process should be a large one with all stakeholders represented, or a smaller group that would then lead a broad consultation process with other relevant stakeholders. The minutes of the Utrecht meeting records a recommendation of the smaller group model "in order to keep the process manageable and moving forward, while designing a rigorous, broad consultation process for the draft standards and technical guidance documents". Here the BCI standard-setting process diverged from the WWF-initiated roundtables for sustainable palm oil and soy by adopting a more streamlined decision-making process. Rather than have decisions made by a general assembly of all stakeholders, decision-making power was delegated to a small body (the steering committee) which would carry out extensive consultation with a broader range of stakeholders. ${ }^{7}$ Thus, as explained by a consultant that was involved in the early process, a key element of institutional learning was that in order to secure efficiency in the standard-setting processes it was thought more conducive "not to let decisions be made by a massive collective".

This reflects a potential dilemma for global lead firms in extending GPN governance to the base of GPNs through MSIs. If local-level actors such as small-scale farmers and suppliers (for instance, fabric mills, spinners and ginners) are involved in the MSI formulation process from the outset, their demands would likely include issues such as predictability of demand, increased cotton prices for their extra efforts in complying with the BCI standard, and compensation for ensuring traceability of the BCI cotton through the GPN. While this might be ideal from the perspective of civic concerns related to inclusion and transparency in decision-making, it is likely to compromise the industrial concern with efficiency in decision-making processes as brand 
priorities would likely be challenged by these stakeholders from the South invoking different visions of what was to count as the new 'normal' in sustainable cotton production and trade.

In the early stages of the BCI standard formulation process, the industrial concern with maintaining decision-making efficiency was thus at the core of the process of drafting the standard through the adoption of the smaller group model while the ideal civic convention of a more inclusive, transparent and participatory process was relegated to a broader consultation process for the draft standard itself. The smaller group which was delegated decision making power was dominated by Western organisations (European and American) and heavily concentrated around the specific stakeholder categories of NGOs and brands.

The Steering Committee along with the BCI secretariat ${ }^{8}$ thus played a key role in terms of framing the standard. As some earlier WWF-initiated MSIs had created standards by developing production principles and criteria, this approach was also adopted. However, instead of having the standard developed by a global expert panel, the BCI production principles and criteria were first drafted by the secretariat, then approved by the Steering Committee, and subsequently discussed in regional working groups in two rounds of consultation.

As a consultant centrally involved in the process at the time conveyed:

“..If I wanted genuine expertise for a global initiative given that there is a regional diversity in cotton production...we're going to need a huge group of people and how are you going to find a group small enough to manage but big enough to have all the expertise. We will ultimately need to test this standard and find places to test it. So I quickly came to the conclusion that we needed a much more regional approach to defining the standard. Rather than having a global group that somehow had to be experts in cotton farming in all the represented group of countries it is far better to do that at the regional level or the country." 
This could thus be interpreted as an attempt by the BCI at embracing the civic ideal of inclusion and participation, and seeking to avoid excluding local producers and workers from the process of normalizing GPN governance. In setting up regional level working groups, the steering group ranked cotton producing countries according to production, profile (small holder/large holder), geographic spread and potential or current interest in the BCI. Hence, it was decided to establish regional working groups in India, Pakistan, West Africa (as a region) and Brazil, involving broader sets of actors such as government officials, farmers, garment/textile suppliers, NGOs and labour representatives.

Key objectives of the regional consultations were stated in the first regional meeting in Pakistan in 2007 as consisting of "Confirmation of applicability of the global environmental principles within the Better Cotton Global Framework", "Refined criteria under each of the Principles" and identification of the best management practices applicable to the local context. As such, although the BCI carried out a very extensive stakeholder consultation process, there were limitations as to what the stakeholders were actually consulted on. Thus the consultation was mainly to confirm the applicability of the draft principles and to develop locally suitable criteria and management practices. The consultation process was not intended to discuss issues such as different understandings of sustainability per se, or in other words qualifications of the common good. Nor were the decisions about going for scale and not including a farmer premium up for discussion in the consultation process (more on this in the next section).

When comparing the different drafts of the standard, it is noticeable that the principles have not changed much from the initial steering committee draft. Hence, in terms of decision-making efficiency, looking at the feedback from the first round of consultations, the input noted from the different country groups related mainly to practical or technical suggestions for how to formulate criteria and indicators. A notable exception that seems to have gone beyond the draft principles 
presented for discussion by the BCI were by the group from Pakistan which suggested an additional criteria "based on the need for a fair and equitable marketing system" (BCGF 2007). This civic idea of fairness and equity in GPN governance was not adopted by the steering committee and illustrates the limits of the compromises reached with civic expectations.

If we summarize how the trade-off between stakeholder inclusion and process efficiency was handled in the case of formulating the BCI standard system between 2003 and 2009, we can state that the process was inclusive to the extent that a very broad range of GPN actors from various regions and countries were part of the process of GPN normalizing. However, this was balanced against the industrial need to ensure process efficiency as the main decision-making authority rested with the international steering committee dominated by European and North American based-brands and NGOs. Thus, in the compromise forged, the civic ideal of MSI inclusiveness and participatory standard-making was instead institutionalized through the regional working groups where a broader group of Southern stakeholders provided feedback and inputs to the main ideas articulated in the draft production principles, criteria and other parts of the BCI system. As we shall see in the next section, the process of normalizing particular conventions in cotton GPN governance through the BCI also came to relate more directly to more traditional lead firm concerns with drivenness.

\section{Balancing Scalability and Stringency of the Standard System}

The second trade-off that we identified in our theoretical section as facing multistakeholder initiatives was the need to balance the scalability and stringency of the standard. It was clear from the beginning that the international brands and retailers that were part of the standard formulation process were keen on ensuring that the BCI standard system would mean that Better Cotton was scalable as illustrated here in the words of one of the brand members of the steering committee: 
"One thing that was put on the table from the beginning was that this has to be in the spirit of being scalable, it should be functional in many countries and areas, scalable, scalable, scalable, cost-efficiency, economies of scale".

This can be related back to a more traditional understanding of lead firm governance of GPNs where retailers are concerned about 'driving' their production networks - in this case extending their control over quality, quantity and stability of supply. As was explained by a former BCI staff member who was centrally involved in the convening of the BCI steering committee:

"All of them (i.e. the retailers and brands) had experienced sourcing organic and fair trade cotton. They knew that it was hard and cost quite a lot of money. There was a shortage of supply. It was hard for the farmers to comply with the standard. So they wanted something that dealt with the rest."

As already mentioned, the focus on scalability relates to an industrial narrative which posits that change is only significant if it is scalable - a viewpoint which was shared by the large buyers and donor agencies involved in the BCI. This was evident already from the first official meeting in 2004 in Sigtuna, Sweden where the discussion around how to achieve sustainable cotton was founded on some basic assumptions:

"By identifying and focusing on a handful of issues, which together might capture $80 \%$ of the key global sustainability impacts, significant change can be achieved...The greatest change can be effected by addressing mainstream industry practice, rather than niche markets" (Sigtuna Report, 2004).

In order words, in the process of GPN normalization, Better Cotton was framed in line with industrial conventions, emphasizing that in order for the initiative to be able to achieve 
'significant change' towards more sustainable cotton production it had to be set up in such a way that it could reach scale. To reach scale and not from the outset exclude large numbers of smallholders from participating, it was decided that instead of requiring compliance with an absolute set of very stringent criteria, the BCI standard entry demands would be at relatively basic level but then focus on continuous improvement (more on this in the next section).

Hence, for the large buyers, GPN governance concerns about increasing the supply of Better Cotton by making it feasible to implement for small farmers placed clear limits on how stringent (in terms of the scope and depth of issues demanded by the standard) the Better Cotton Standard could be. In the words of a brand representative:

"From the outset, this was an initiative that would not try to address everything but work according to an 80-20 rule.....If you address 80 percent of the issues (i.e. related to sustainable cotton production), you have probably already addressed most of the problems.... You could reduce and improve water and pesticide use, soil quality, etc. taking those major chunks rather than doing the nitty-gritty."

The trade-off between scalability and ensuring the stringency of the standard also dominated other parts of the standard formulation process. For instance, there were limits on how stringent the standard could be on labour issues if it was realistically to involve a sufficiently large number of small farmers. Furthermore, some of the decent work principles (on which the BCI labour content is based) were inherently difficult to implement in a smallholder setting where informal casual employment relations are the norm.

In response to some of the concerns raised by farmer representatives in the regional working groups, the BCI made the labour standard aspects of GPN governance less contentious by 
rewording the principle related to Decent Work. The $6^{\text {th }}$ principle presented by the BCI originally read "the Better Cotton Initiative will respect and promote decent work". However, it was suggested by the social scoping group from Pakistan that this principle "is solely to 'promote' Decent Work" (BCGF 2007), a significant rewording which was accepted in what was to become the official BCI standard and which again illustrates the limits to the incorporation of civic expectations in 'normalizing' GPN governance.

The civic aspect of what eventually came to count as 'normal' in governing on-farm labour relations was also influenced by differentiation between which social aspects of the standard were applicable to smaller and larger farms. The BCI established three categories of farms ${ }^{9}$ : smallholders (<20ha under cotton), medium farms (20-200ha) and large farms (>200ha). Very few requirements related to Decent Work applied to the category of smallholder farmers in which the large majority of BCI farmers fall in countries like India and Pakistan. For example, hired workers on smallholder farms did not have the right to Freedom of Association or Collective Bargaining, they were not covered by any health and safety requirements apart for having access to portable and washing water, there were no requirements regarding the way they were remunerated, and they were not covered by any requirements related to disciplinary practices. ${ }^{10}$ The rationale behind this was that meaningful application of labour standards to smallholder setting is challenging as boundaries between self-employment, family and waged labour are often fluid. It was also based in an assumption that smallholder farmers "... are not structurally dependent on permanent hired labour...". This assumption is a widespread one however, our research on the BCI standard, involving 600 hundred farmers and workers in India and Pakistan revealed that smallholders are indeed - in many cases - dependent on hired labor (LundThompsen, 2018). ${ }^{11}$ 
As mentioned, the scalability rationale is also closely related to lead firm governance concerns about cost-efficiency. This is illustrated, for instance, by the strong commitments of particularly the corporate members of the BCI standard setting process but also by some of the NGOs not to pay a premium for Better Cotton. The prevailing narrative was that efficiency and quality gains would more than offset any standard related increase in producer costs. This was expressed by one of the NGO participants who took part in the initial years of the BCI steering committee:

\begin{abstract}
"From the beginning... we wanted to get beyond the niche market. There could not be a premium as a given on the table. The premium would depend on supply-demand relations. Early adopters and verifiers would obtain a premium. Our theory was that people would be able to make more money using less chemicals, fertilizers and water."
\end{abstract}

The commitment to not giving farmers a price premium for the production of Better Cotton was echoed by a brand representative in the BCI steering committee:

\begin{abstract}
"There were a lot of discussions that it should be for the commodity, it should take into consideration people's profit, there should not be a premium attached to it. That was probably mine and X brand's biggest contribution. At the time we already had a cotton project in (a country in South Asia) where we saw how much it cost to train farmers. Secondly, how much it cost to get hold of the cotton you produced. Thirdly, we saw how much farmers in $Y$ country could improve their incomes and margins with better farming practices. So why on earth should we pay a premium?"
\end{abstract}

In our view, however, the commitments of the brands to sell sustainable products without any price increase for farmers are in themselves a reflection of underlying power dynamics in cotton GPNs. ${ }^{12}$ It should be noted, however, that in the BCI scheme buyers actually do adopt some of 
the verification costs through the Volume-Based Fee that retailer and brand members pay. When a member declares $\mathrm{x}$ amount of Better Cotton sourced, they pay the fee into the Growth and Innovation Fund. The fund then redistributes this funding to partners who build farmer capacity and pays for third party verification for smallholders and medium farms (large farms pay their own verification fees).

In sum, the central actors involved in the formulation of the BCI standard system were mainly European and North American brands and NGOs that had decided on key issues related to GPN governance reflecting industrial and market concerns about scale and cost efficiency. To realistically enable sustainability verification of a large number of small farmers there were limits on how stringent the Better Cotton Standard could be - or in other words which compromises could be forged with civic expectations.

\section{Balancing Capacity Building and Auditing}

The third potential policy trade-off facing those designing the BCI standard system was whether GPN governance was most effectively exercised through an auditing or a farmer capacity building approach when it came to making cotton production more sustainable at base of the network. There was no immediate answer to this question and instead the process of designing the BCI's assurance system (i.e. their monitoring and control system) involved in-depth reflection processes and a level of policy learning. In relation to the capacity building of cotton farmers, research and field experiments - particularly the partnership between IKEA and WWF in India and Pakistan on Better Management Practices in the area of sustainable cotton production played an important role in informing the standard formulation process. As an NGO representative involved in the implementation of sustainable cotton projects in Pakistan explained: 
"We had first-hand experience so we were sharing results from our small (i.e. farmer capacity building) projects. There were companies who were doing their own homework. There was lots of information available from other organization".

At the same time, the BCI was also part of a learning process related to the assurance program. According to a consultant who was involved in advising the BCI on how it should design its assurance approach, the key challenge that the BCI faced was how to get the balance right between building the capacity of farmers to comply with the BCI standard and monitoring their performance against a measurable set of production principles and criteria:

\begin{abstract}
"One of the real challenges we had was working out whether this was a certification scheme or a capacity building development program or is it something between the two. That still is a real tension with BCI... Simply laying down a law and expecting extremely poor and vulnerable households to abide by that law without capacity, without knowledge and without doing something about their role in the value chain was at best ineffective and at worst very counterproductive."
\end{abstract}

The emphasis on capacity building efforts is thus partly an ideal civic expectation present in many MSIs that focuses upon how they will enable poor and vulnerable local producers (and workers) to comply with the standard through capacity building not policing. The assumption here is that the reason that producers do not act in a sustainable manner is primarily due to lack of knowledge. This idea of "responsible" and "willing" actors who will act sustainably if only they are taught how is thus indirectly positing that questions of power and resources can somehow be ignored when discussing sustainability. A similar point of view was expressed by a former BCI staff member who took a lead in facilitating the process of formulating the BCI standard: 


\begin{abstract}
"At the time, we firmly believed that auditing does not work. Auditing is not a capacity building approach. Auditing just costs a lot of money but you need it for the perception of the consumer. But otherwise it is a useless process...So the process we wanted them to go through was a bit more intensive. These farmers had to complete a self-assessment process, learning groups. It was a very bottom-up process with minimal auditing."
\end{abstract}

On the other hand, MSIs also operate within a context of GPN power relations. Funders of such initiatives, whether they are (inter)governmental donors, private funding agencies, consumers or international brands/supermarkets, also need some form of accountability. In other words, they require 'proof' that the money they are investing in MSIs leads to the desired end results. The format of this 'proof' generally involves industrial values of oversight and control in the form of auditing. For this purpose, most MSIs develop different systems for data gathering at the level of implementation and internal/external monitoring visits to verify (and often certify) that the reported activities and results are actually obtained.

In short, the BCI wound up with a kind of compromise between engaging in a more complianceoriented strategy - an auditing approach - and a cooperation based approach to sustainability standards. Here, a central idea was that the BCI would not be measuring the absolute performance of BCI farmers in terms of their level of compliance with the BCI standard. Instead the BCI would focus on ensuring the continuous improvement of farmers in relation to meeting the production principles and criteria laid down in the BCI standard system. This was explained by an NGO staff member:

"Another area that was of concern was whether you measure performance and have people in or out or whether you just encourage producers to get better through a continuous improvement program. In the BCI, the decision was made not to measure specific 
performance and either approve or not approve (i.e. certify farmers) but rather to look at overall performance and continuous improvement."

This focus on continuous improvement (as opposed to actual performance outcomes) in line with the focus on promoting (as opposed to respecting) decent work described earlier, can again be related to the industrial scale imperative and the challenge of verifying large numbers of small farmers as sustainable (see Bartley et al. 2016:23 for a similar argument with regards to labour standards which illustrates how the logic of assurance systems coincide with the interests of lead firms "who would suffer if large swaths of key markets were considered off limits").

The BCI sought to address the potential trade-off between adopting a more compliance-based approach and a more cooperation-based approach to sustainability standards by envisioning that data gathering processes (as a way of demonstrating compliance with the BCI standard system) could actually become part of the capacity building process of farmers. In the words of a former BCI staff member:

"Because the farmers should be gathering the data, anyway, in order to realize the benefit of what they are doing. So it is part of capacity-building. You are building their capacity to measure and make more money from their farms which they may not necessarily know how to do. We had farmer field books. The few farm projects that I managed to visit, the farmers were most proud of the field books. They would say come look at my field book from the back, we have our beneficial insects, we made our calculations and they are very proud of saying that I know now that I made this much more money this year. That was just like a nobrainer." 
In this way, capacity building partly built on civic ideas of empowering vulnerable people and partly on industrial notions of measuring and recording progress. In short, those centrally involved in the design of the BCI conceived of the possibility for combining auditing and capacity building approaches. The interesting question is then whether this delicate balance between auditing and capacity building could be maintained once the standard system was scaled up.

\section{Conclusion}

In this article, we asked whether through multistakeholder initiatives it is possible to address the limitations of the criticized compliance approach by moving towards cooperative methods while at the same time catering to the needs of lead businesses supplying the mainstream market. In this context, our analysis contributes to the literature on MSIs in GPNs by conducting the first empirical analysis of the BCI standard setting process. In theoretical terms, we also advanced this literature by combining a conception of GPN governance as 'normalizing' with a more traditional understanding of GPN governance as 'driving', thus identifying three institutional tensions inherent in MSIs that seek to rapidly upscale and mainstream the production of more sustainable commodities: (a) stakeholder inclusion vs. process-control/efficiency; (b) stringency of the standard vs. scale of production; and (c) capacity building vs. auditing. This allowed us to analyse how the standard setting of the Better Cotton MSI between 2003 and 2009 involved broader tensions related to what values were to define the terms of production at the base of the cotton GPN and hence some of the rules and conditions of participation in that GPN.

An analysis of how these tensions were negotiated in the BCI shows that particularly industrial conventions of quality (here in the sense of particular understandings of sustainable production which are seen as legitimate) were naturalized in the formulation of the BCI standard. The industrial values of efficiency and scalability dominated the BCI standard setting process and 
although the settlements reached included some compromises with civic and market expectations, our analysis has also shown the exclusion of particular civic ideas related to inclusive decision making, redistribution in the value chain and labour rights issues on smallholder farms.

Most notably, the industrial imperative of scalability has been influential in shaping the BCI system. In order to be able to reach scale, and not from the outset exclude large numbers of smallholders from being verifiable, capacity building is prioritized and instead of certification, the $\mathrm{BCI}$ focuses on continuous improvements and verification to a basic level of requirements (excluding more stringent requirements). One could also see the decision to have buyers adopt verification and capacity building costs (through the Volume-Based Fee) as necessary not to exclude large numbers of smallholders from being verifiable.

The broader implication for conceptualizing MSIs in GPNs is that sustainability standard setting processes, including the described dilemmas, can be perceived as attempts at normalizing new modes of GPN governance in ways that are circumscribed by the wider drivenness of the GPNs. In other words, the settlements reached and particularly the naturalization of industrial values of efficiency and scalability are not only compatible with lead firm concerns about extending their control of the GPN to cotton fields and primary-level production in the South; they also shift the purpose and goal of sustainability away from more radical environmental and social goals (like addressing unfairness in global trade) towards the need to create business value (see also Ponte forthcoming; Humes 2011). For lead firms, the inclusion of a vast number of otherwise nonverifiable producers in the GPN for sustainable cotton creates opportunities for protecting and enhancing brand value and for increasing sales of sustainable products. Furthermore, enhanced control over a large fraction of the bottom tiers of the cotton GPN can be leveraged towards traceability, insurance of product quality, and security of supply. In the process, the BCI enables 
capacity building of farmers and inclusion of otherwise marginalized smallholders in the sustainability strand of the GPN.

More broadly, we argue that the competing policy imperatives identified are very likely to be transferrable to other mainstream, standard-setting MSIs that are aiming to scale up the production of sustainable commodities. The precise institutional settlement that results from the negotiations between different actors and approaches to social and environmental sustainability will vary across the different MSIs and importantly should always be seen as temporary settlements. In our view, it is thus not that MSIs can avoid navigating these policy trade-offs, but rather that the ways in which they seek to bridge these competing policy imperatives will influence not only GPN governance, but also their ability to achieve their ultimate mission.

In other words, we hypothesize that these trade-offs are likely to influence the 'on-the ground' implementation of sustainability standards that aim at achieving global, industry-wide transformation in the following ways:

- For sustainability standards aiming at promoting large-scale global industry-wide transformation, the concern with rapidly upscaling sustainable commodity production might compromise the rigor with which the standards are actually implemented on the ground in the South. As such, only limited changes might occur at the field level in terms of more sustainable commodity production;

- Finally, as sustainability standard systems rapidly seek to increase the number of farmers that are verified, the result could be that farmers are licensed as engaged in more sustainable forms of commodity production before their capacity has actually been sufficiently built to comply with these standards. In other words, there is a risk that these MSIs become 'greenwashing initiatives'. 


\section{References}

AFL/CIO (2014). Responsibility Outsourced: Social Audits, Workplace Certification, and Twenty Years of Failure to Protect Worker Rights, AFL-CIO, Washington, D.C.

Alexander, R. (2016). Sustainability in Global Production Networks: Rethinking Buyer-driven Governance, PhD Thesis, University of Manchester, UK.

Auld, G., Renckens S. \& Cashore B. (2015). Transnational private governance between logics of empowerment and control. Regulation and Governance 9(2), 108-124.

Bartley, T. (2007). Institutional Emergence in an Era of Globalization: The Rise of Transnational Private Regulation of Labor and Environmental Conditions. American Journal of Sociology 113(2), 297-351.

Bartley, T. (2011). Transnational governance as the layering of rules: intersections of public and private standards, Theoretical Inquiries in Law 12(2), 517-542.

Bartley, T. (2018). Rules without Rights: Land, Labor, and Private Authority in the Global Economy. Oxford: Oxford University Press.

Bernstein, S. \& Cashore, B. (2007). Can non-state global governance be legitimate? An analytical framework. Regulation and Governance, 1(4), 347-371.

Better Cotton Initiative (2015, June 14). Key Facts. Retrieved from http://bettercotton.org/wpcontent/uploads/2015/02/BCI-Key-Facts-2015_2.pdf.

Better Cotton Initiative (2016a, June 14). Chain of Custody Guidelines and Traceability System, Retrieved from http://bettercotton.org/wp-content/uploads/2014/01/Slides_BCI-Chain-ofCustody-and-Traceability-System.pdf

Better Cotton Initiative (2016b, April 4). BCI 2015 Annual Report, BCI, Geneva. Retrieved from http://bciannualreport.org/ 
Better Cotton Initiative (2018), BCI Annual Report 2017, BCI, Geneva, Retrieved from https://2017.bciannualreport.org/wpcontent/uploads/2018/10/BCI_2017_Annual_Report_PDF.pd f

Black, M. (2016). King Cotton in International Trade - the Political Economy of Dispute Resolution at the WTO. Brill Nijhoff, Boston.

Boltanski, L, \& Thévenot, L. (2006). On Justification: Economies of Worth. Princeton: Princeton University Press.

Brown, H.S., De Jong, M. \& Lessidrenska, T. (2009). The rise of the Global Reporting Initiative: a case of institutional entrepreneurship. Environmental Politics 18(2), 182-200.

Cheyns, E. (2014). Making 'minority voices' heard in transnational roundtables: The role of local NGOs in reintroducing justice and attachments. Agriculture and Human Values, 31(3), 439-453.

Cheyns, E. \& Riisgaard L. (2014). The exercise of power through multi-stakeholder initiatives for sustainable agriculture and its inclusion and exclusion outcomes. Journal of Agriculture and Human Values 31(3), 409-423.

Coe, N.M. \& Yeung, H.W.C. (2015. Global Production Networks: Theorizing Economic Development in an Interconnected World. Oxford University Press, Oxford.

Dallas, M., Ponte, S. \& Sturgeon, T. (2017). A Typology of Power in Global Value Chains, Working Paper, no. 92, Department of Business and Politics, Copenhagen Business School, Copenhagen.

Dauvergne, P. \& Lister, J. (2013). Eco-business: A big-brand takeover of sustainability. Cambridge, MA, MIT Press. 
Etzion, D. \& Fabrizio, F. (2006). Institutional Entrepreneurship through Voluntary Standard Setting: The Case of the Global Reporting Initiative, Working Paper Series IESE Barcelona 1(1), $55-84$

Ferrigno, S. (2016). Mind the Gap: Towards a More Sustainable Cotton Market, Pesticide Action Network, UK, Solidaridad, and WWF, Brighton.

Fransen, L. (2011). Multi-stakeholder governance and voluntary programme interactions: legitimation politics in the institutional design of Corporate Social Responsibility. SocioEconomic Review, 10(1), 163-192.

Gereffi, G. (1994). The organization of buyer-driven global commodity chains: how US retailers shape overseas production networks. In: Gereffi G. \& Korzeniewicz M. (Eds.), Commodity chains and global capitalism. Praeger, Westport, CT, 95-122.

Gereffi, G., Humphrey, J. \& Sturgeon, T. (2005). The governance of global value chains. Review of International Political Economy, 12 (1), 78-104.

Gibbon, P. (2001). Upgrading Primary Production: A Global Commodity Chain Approach. World Development 29(2), 345-63.

Gibbon, P. \& Lazaro, E. (2010). Global agro-food standards and Africa: An introduction. In Gibbon, P., Lazaro, E. \& Ponte, S. (eds.). Global trade and agro-food standards: challenges for Africa. Palgrave MacMillan, Basingstoke and New York.

Gibbon, P., Bair, J., \& Ponte, S. (2008). Governing global value chains: an introduction. Economy and Society, 37(3), 315-338.

Gibbon, P. \& Riisgaard, L. (2014). A new system of labour management in African large-scale agriculture. Journal of Agrarian Change, 14(1), 94-128. 
Gilbert D.U., Rasche, A. \& Waddock, S. (2011). Accountability in a Global Economy: The Emergence of International Accountability Standards. Business Ethics Quarterly, 21(1), 23-44

Humes, E. (2011). Force of nature: The unlikely story of Wal-Mart's green revolution. New York, Harper Business.

Humphrey, J. \& Schmitz, H. (2002). How does insertion in global value chains affect upgrading in industrial clusters? Regional Studies, 36(9), 1017-27.

IIED/Proforest (2004). Better Management Practices and Agribusiness Commodities. Phase Two Report: Commodity Guides. IIED, Proforest, Rabobank International, London.

Ingenbleek, P. \& Meulenberg, M.T.G. (2006). The battle between 'good' and 'better': a strategic marketing perspective on codes of conduct for sustainable agriculture. Agribusiness, 22(4), 451473.

International Centre for Trade and Sustainable Development (ICTSD 2013). Cotton Trends in Global Production, Trade and Policy, Information Note, May, ICTSD, Geneva.

Levy, D. (2008). Political Contestation in Global Production Networks. Academy of Management Review, 33(4), 943-963.

Levy, D. \& Scully, M. (2007). The institutional entrepreneur as modern prince: the strategic face of power in contested fields. Organisation Studies, 28(7), 971-991.

Levy, D., Reinecke, J. \& Manning (2016). The Political Dynamics of Sustainable Coffee: Contested Value Regimes and the Transformation of Sustainability. Journal of Management Studies, 53(3), 364-401.

Locke, R.M. (2013). The Promise and Limits of Private Power: Promoting Labor Standards in a Global Economy. Cambridge University Press, Cambridge, UK. 
Locke, R.M. \& Romis, M. (2007). Improving work conditions in global supply chains. MIT Sloan Management Review, 48(2), 54-62.

Loconto, A. \& Fouilleux, E. (2013). The politics of private regulation: ISEAL and the shaping of transnational sustainability governance. Regulation and Governance, 8(2), 166-185.

Lund-Thomsen, P. \& Lindgreen, A. (2014). Corporate Social Responsibility in Global Value Chains: Where Are We Now and Where Are We Going? Journal of Business Ethics, 123(1), 1122

Lund-Thomsen, P. \& Nadvi, K. (2010). Clusters, chains, and compliance: corporate social responsibility in football manufacturing in South Asia. Journal of Business Ethics, 93(2), 201-222.

Lund-Thomsen, P. \& Coe, NM. (2015). Corporate social responsibility and labour agency. Journal of Economic Geography, 15(2), 275-296.

Luhtakallio, E. \& Thévenot, L. (2018). Politics of engagement in an age of differing voices. European Journal of Cultural and Political Sociology, 5(1-2), 1-11

Macdonald, K. (2007). Globalising justice within coffee supply chains? Fair trade, Starbucks and the transformation of supply chain governance. Third World Quarterly, 28 (4), 793-812.

Maguire, S. \& Hardy, C. (2006) The emergence of new global institutions: a discursive perspective. Organization Studies, 27(1), 7-29.

Maguire, S., Hardy C. \& Lawrence, T. (2004). Institutional entrepreneurship in emerging fields: HIV/AIDS treatment advocacy in Canada. Academy of Management Journal, 47 (5), 657-679.

McAdam, D. \& Scott, W.R. (2005). Social movements and organization theory. Cambridge University Press, Cambridge.

Nadvi, K. (2008). Global standards, global governance and the organization of global value chains. Journal of Economic Geography, 8(3): 323-343. 
Nelson, V. \& Tallontire, A. (2014). Battlefields of ideas: changing narratives and power dynamics in private standards in global agricultural value chains. Agriculture and Human Values 31(3), 481-497.

PAN UK, Solidaridad, \& WWF (2017). Sustainable Cotton Ranking - Assessing Company Performance. PAN UK, Solidaridad, and WWF, Brighton.

Ponte, S. (2013). 'Roundtabling'sustainability: Lessons from the biofuel industry. Geoforum, 54, 261-271.

Ponte, S. (Forthcoming). Green Capital, Brown Environments Business, Power and Sustainability in a World of Global Value Chains. Draft book manuscript for Zed Books

Ponte, S. \& Gibbon, P. (2005). Quality standards, conventions and the governance of global value chains. Economy and Society, 34:1, 1-31

Quark, A. (2011). Transnational Governance as Contested Institution-Building: China, Merchants, and Contract Rules in the Cotton Trade. Politics \& Society, 39(1), 3-39

Quark, A.A. (2013). Global Rivalries: Standards Wars \& the Transnational Cotton Trade. Chicago: University of Chicago Press.

Rasche, A. (2012). Global Policies and Local Practice: Loose and Tight Couplings in MultiStakeholder Initiatives. Business Ethics Quarterly, 22(4), 679-708

Raynolds, L. (2017). Fairtrade labour certification: the contested incorporation of plantations and workers. Third World Quarterly, 38(7), 1473- 1492.

Raynolds, L. T. (2018). Fairtrade Certification, Labor Standards, and Labor Rights: Comparative Innovations and Persistent Challenges. Sociology of Development 4(2), 191-216.

Riisgaard, L. (2011). Towards More Stringent Sustainability Standards? Trends in the Cut Flower Industry. Review of African Political Economy, 38(129), 435-453. 
Riisgaard, L. \& Gibbon, P. (2014). Labour management on contemporary Kenyan cut flower farms: foundations of an industrial-civic compromise. Journal of Agrarian Change, 14(2), 260285.

Scott, W.R. (2014). Institutions and Organizations - Ideas, Interests and Identities. Stanford University, Sage Publications, London.

Sneyd, A. (2014). When governance gets going: certifying 'Better Cotton' and 'Better Sugar', Development and Change, 45(2), 231-256.

Talbot, J.M. (2009). Grounds for Agreement. The Comparative Advantages of Tropical Commodity Chain Analysis. In Bair J (ed.). Frontiers of Commodity Chain Research. 93-109. Stanford University Press, Stanford, CA.

USDA (2016, April 4). China State Reserve Auctions Off to Strong Start, Cotton - World Markets and Statistics, United States Department of Agriculture, USDA, Washington. D.C. Retrieved from http://apps.fas.usda.gov/psdonline/circulars/cotton.pdf

Utting, P. (2002). Regulating business via multi-stakeholder initiatives: a preliminary assessment, UNRISD, Geneva.

Worldwide Fund for Nature (WWF) (2009). Cleaner, Greener Cotton - Impact and Better Management Practices, WWF, Zeist.

Yeung, H.W.C. \& Coe, N.M. (2015). Toward a dynamic theory of global production networks. Economic Geography, 91(1), 29-58. 


\section{Endnotes}

${ }^{1}$ Approximately 30 percent of world cotton production is traded internationally before it is used in the later, more value-adding stages (USDA, 2016).

2 In December 2008 it was decided to change the self-selected Steering Committee into the elected BCI council. This happened after five years of standard making and close to the time when the BCI standard had to be endorsed.

3 In short, the compliance-based approach entails retailers/supermarkets/other types of importers developing a code of conduct, then requesting their first tier suppliers to comply with the code. The next step involves auditing of supplier compliance with the code of conduct. In cases of noncompliance, the supplier is given a certain period to implement an action plan to correct deviations from the buyer code of conduct. In case of continued supplier non-compliance at the end of the specified period, the buyer is supposed to cut ties with its supplier, punishing 'bad' behavior whereas compliant suppliers are to be rewarded with more business (Lund-Thomsen \& Lindgreen, 2014).

${ }^{4}$ Boltanski and Thévenot (2006) also identify conventions relating to 'inspiration' and 'fame'; however, these are not deemed relevant for the analysis conducted in this article.

5 It is beyond the scope of this paper to elaborate on the "grammars of commonality according to which actors agree and disagree when looking for legitimacy" (Luhtakallio and Thévenot, 2018: 5) - an extension of the conventions framework. However it is important to note that from such a perspective, MSIs are limited to the format of negotiations between different interests while discharging attempts at specifying a common good or debating principles of justice/injustice (Cheyns, 2014).

${ }^{6}$ It should be noted that this account of events was contested by another former member of the BCI steering committee who thought that a British development NGO and a Dutch development NGO both stayed on the steering committee for a significant amount of time. 
${ }^{7}$ At the Utrecht meeting, the following conception of a Steering Committee (initially named a steering group) was presented: “....the Steering Group is essentially self-selecting on the basis of interest and commitment. Every effort should be made to ensure that people/institutions from all steps of the cotton chain are represented, with a probable bias towards farmers and brands. In some cases farmer groups may be represented by researchers who work closely with them" (Utrecht, 2005). It should be noted that the only person elected was the chair of the Steering Committee which was elected by the committee members.

${ }^{8}$ After the second meeting in July 2005 the steering group was formed and it was agreed that professional paid help was needed to facilitate the BCI. To begin with a consultant specializing in agricultural agronomy was hired and not long after that another consultant to head what would become the BCI secretariat followed by a consultant on labour issues in 2007. ${ }^{9}$ http://bettercotton.org/wp-content/uploads/2014/10/production-principles-and-criteria.pdf accessed June 2017

${ }^{10} \mathrm{http}: / /$ bettercotton.org/wp-content/uploads/2014/10/production-principles-and-criteria.pdf $\underline{\text { accessed June } 2017}$

${ }^{11}$ Recently similar findings have been reported from other smallholder export commodities such as tea and coffee (Riisgaard and Okinda, 2017 and Cramer et al., 2014)

12 Another argument could be that if adoption of the better practices leads to an improved level of profitability, then there is an inherent incentive for the farmer to continue to implement that practice. If that is the actual effect of the standard then it is more potentially more sustainable than having implementation depend on a premium. 